\title{
Intracranial pressure in central nervous system infections and cerebral ischaemia of infancy
}

\author{
K J GOITEIN, Y AMIT, AND H MUSSAFFI
}

Paediatric Intensive Care Unit and Department of Paediatrics, Hadassah University Hospital, Jerusalem, Israel

SUMMARY Intracranial pressure was continuously monitored in 23 patients aged between 24 hours and 20 months. Fourteen had severe infections of the central nervous system (CNS) and 9 sustained prolonged cerebral ischaemia. The intracranial pressure measured at catheter placement was not a reliable indicator of the intracranial pressure that developed during the course of the disease. The mean maximal intracranial pressure in infants with CNS infection $(57.4 \pm 25.8 \mathrm{mmHg})$ was significantly higher than in infants with cerebral ischaemia $(34.6 \pm 17.6 \mathrm{mmHg})$. Mortality in CNS infections $(36 \%)$ was closely correlated with the degree of increased intracranial pressure, while mortality in cerebral ischaemia $(67 \%)$ was not. Continuous monitoring of intracranial pressure enables treatment to be started early so that intracranial pressure can be reduced and adequate cerebral perfusion pressure maintained. This may help to reduce morbidity and mortality.

Continuous monitoring of intracranial pressure (ICP) has become an integral part of the management of childhood diseases that are accompanied by increased ICP. ${ }^{1-3}$ If not continuously monitored, undiagnosed increases in ICP may cause brain damage and carry a grave prognosis with pronounced neurological sequelae and high mortality. The clinical signs are often unreliable and sporadic measurement of ICP inadequate, since rapid and extreme changes may occur throughout the course of the disease. Continuous monitoring of ICP enables early initiation of treatment directed at reducing the ICP to normal levels. Extensive experience in the monitoring of ICP has been reported in head trauma, brain tumours, and Reye's syndrome using invasive methods. More recently application of non-invasive methods has enabled monitoring in normal newborn infants and in those at risk. ${ }^{45}$ There is a lack of clinical data on the ICP in infants with infections to the central nervous system (CNS), and in infants who have sustained prolonged cerebral ischaemia. ${ }^{26}$ Physicians are reluctant to use the more dangerous invasive catheter placement techniques in patients who do not need a craniotomy and the non-invasive methods of ICP monitoring are often not applicable. The transcutaneous transducers, used in the noninvasive methods, require for accuracy a wide open fontanelle and are dependent on difficult to establish application force. ${ }^{7}$

We report our experience with continuous monitoring of ICP in small infants with severe infections of the CNS and cerebral ischaemia.

\section{Materials and methods}

During the period September 1980 to March 1982 the ICP was continuously monitored in 23 patients through a percutaneously placed subdural catheter. ${ }^{8}$ Using the same technique as for subdural tap, a 22-gauge Quick Cath (Travanol Laboratories, Irvine, $\mathrm{Ca}$ ) was introduced into the subdural space. It was then connected, via non-compliant tubes, to a pressure transducer and the ICP displayed on a bedside monitor. Simultaneously blood pressure was monitored through an arterial line and displayed on the same monitor. ICP and blood pressure were recorded hourly, but if any acute change took place they were recorded more frequently. Cerebral perfusion pressure was calculated and recorded at the same time. The indications for monitoring ICP were based on clinical signs of increased ICP, computerised tomography, and a Glasgow coma scale $^{9}$ less than 7 . We used a modification of that scale for small infants with crying as a criterion instead of verbal response. Crying was graded between normal, spontaneous crying and abnormal, high pitched, inappropriate 'cerebral cry'. As the infants presented in deep coma it was not difficult to use the scale. Treatment was initiated if ICP exceeded $20 \mathrm{mmHg}$ or if the cerebral perfusion pressure fell 
below $40 \mathrm{mmHg}$. Acute, short-term changes were not treated. Before any procedure that might be accompanied by extreme increases in ICP - such as intubation, endotracheal suctioning, or physiotherapy, ${ }^{10}$-prophylactic treatment with thiopentone sodium ( $5 \mathrm{mg} / \mathrm{kg}$, single dose) was given. Treatment followed the standard protocol for increased ICP with lasix and hyperventilation. If this failed to reduce ICP to below $20 \mathrm{mmHg}$ within 20 minutes or if cerebral perfusion pressure was below $40 \mathrm{mmHg}$, mannitol was added and finally barbiturates. Dexamethasone was administered, as early as possible, to any patient with cerebral ischaemia in an attempt to prevent cerebral oedema.

Treatment was continued until the ICP had been normal for 24 hours. The subdural catheter remained in place for an additional 24 hours to ensure continued normal ICP.

\section{Results}

The ICP was continuously monitored in 23 patients (Table). The youngest was 24 hours and the oldest 20 months (mean age 5.6 months). Ten of the 14 infants with infections of the CNS had bacterial meningitis, the remaining 4 had encephalitis. All had presented in deep coma (scale 7 or less). Five ( $36 \%$ ) of them died.

All 9 patients with cerebral ischaemia sustained long periods of cardiopulmonary arrest and prolonged efforts at resuscitation. They, too, had presented in deep coma (scale less than 6). The primary disease was sepsis in four, congenital cardiac anomaly in two, prolonged apnoea accompanying status epilepticus in one, birth asphyxia in one, and 'near miss sudden infant death syndrome' in one. Six $(67 \%)$ of them died. The total mortality for all 23 infants was therefore $11(48 \%)$.

Opening pressure (the pressure measured at catheter placement) had been normal (less than $20 \mathrm{mmHg})$ in $11(48 \%)$ of them. In 4 the ICP had remained normal throughout monitoring. The opening pressure varied widely between the two groups of patients. The mean opening pressure was $32.9 \pm 25 \mathrm{mmHg}$ in infants with CNS infections and $18 \pm 7.9 \mathrm{mmHg}$ in infants with cerebral ischaemia. Mean maximal pressure was $57.4 \pm 25.8 \mathrm{mmHg}$ in the former and $34.6 \pm 17.6 \mathrm{mmHg}$ in the latter group. This difference is statistically significant $(\mathrm{P}<0.01)$. The difference between the mean opening and the mean maximal pressure is significant for each group: $P<0.01$ for infants with $C N S$ infections and $\mathbf{P}<0.02$ for those with cerebral ischaemia. Both the mean opening pressure and the maximal pressures were significantly different between patients who survived and those who did not in the CNS infection group $(\mathrm{P}<0.05$ and $\mathrm{P}<0.01$ respectively). In patients with cerebral ischaemia these pressures were not significantly different between survivors and non-survivors.

No complications that could be attributed directly to the monitoring system were noted. The subdural catheter remained in place for between 12 hours and 6 days (mean $3 \cdot 8$ days).

\section{Discussion}

Infectious diseases of the CNS and cerebral ischaemia after cardiopulmonary arrest are often complicated by development of increased ICP which may cause further neuronal damage. Management of such patients is facilitated by continuous monitoring of ICP so that treatment can be initiated if increased ICP is observed. The opening pressure proved to be an unreliable indicator of the maximal ICP as ICP develops during the course of the disease and 5 patients in whom the opening pressure was normal later developed greatly increased ICP, thus once more demonstrating that sporadic measurement of ICP is unsatisfactory in the management of diseases accompanied by increased ICP. It is suggested that the opening pressure depends on the stage of the disease at the time of measurement. The mean opening pressure $(32.9 \mathrm{mmHg})$ in the group of

Table Details and outcome of the 23 patients

\begin{tabular}{|c|c|c|c|c|c|}
\hline \multirow[t]{2}{*}{ Disease } & & \multirow[t]{2}{*}{ Age } & \multicolumn{2}{|c|}{ Pressure $(\mathrm{mmHg})$} & \multirow{2}{*}{$\begin{array}{l}\text { Time that } S C \\
\text { stayed in place } \\
\text { (days) }\end{array}$} \\
\hline & & & Opening & Maximal & \\
\hline \multicolumn{6}{|l|}{ CNS infection } \\
\hline $\begin{array}{l}\text { Survivors }(n=9) \\
\text { Non-survivors }(n=5)\end{array}$ & $\begin{array}{l}\text { Range } \\
\text { Mean } \pm \text { SD } \\
\text { Range } \\
\text { Mean } \pm \text { SD }\end{array}$ & $\begin{array}{l}45 \text { days }-16 \text { months } \\
5 \cdot 9 \pm 4 \cdot 4 \text { months } \\
5-20 \text { months } \\
12 \cdot 8 \pm 6 \cdot 2 \text { months }\end{array}$ & $\begin{array}{l}12-37 \\
24 \cdot 8 \pm 9 \cdot 8 \\
9-86 \\
47 \cdot 6 \pm 37 \cdot 8\end{array}$ & $\begin{array}{l}19-64 \\
46 \cdot 3 \pm 16 \cdot 4 \\
26-96 \\
77 \cdot 2 \pm 29 \cdot 4\end{array}$ & $\begin{array}{l}3-6 \\
4 \cdot 6 \pm 1 \cdot 3 \\
1-6 \\
3 \cdot 6 \pm 2 \cdot 3\end{array}$ \\
\hline $\begin{array}{l}\text { Cerebral ischaemia } \\
\text { Survivors }(n=3) \\
\text { Non-survivors }(n=6)\end{array}$ & $\begin{array}{l}\text { Range } \\
\text { Mean* } \\
\text { Range } \\
\text { Mean } \pm \text { SD }\end{array}$ & $\begin{array}{l}36 \text { hours }-2 \text { months } \\
28 \cdot 8 \text { days } \\
24 \text { hours }-6 \text { months } \\
1 \cdot 3 \text { months }\end{array}$ & $\begin{array}{l}8-29 \\
20 \cdot 0 \\
8-27 \\
15 \cdot 5 \pm 7 \cdot 9\end{array}$ & $\begin{array}{l}37-47 \\
42 \cdot 7 \\
14-67 \\
30 \cdot 5 \pm 20 \cdot 5\end{array}$ & $\begin{array}{l}4-6 \\
4-7 \\
1-4 \\
2 \cdot 3 \pm 1 \cdot 2\end{array}$ \\
\hline
\end{tabular}

*Numbers too small for analysis. $\mathrm{SC}=$ subdural catheter. 
patients with CNS infections was much higher than the mean pressure $(18.1 \mathrm{mmHg})$ in the patients with cerebral ischaemia in whom it could be considered within normal limits. Because of the wide variation this difference was not statistically significant. The difference between opening pressure in the two groups may be due to the fact that the ICP increases early in the course of CNS infections ${ }^{11}$ while brain oedema may develop 18-24 hours after an ischaemic insult.

The mean ICPs measured throughout the period of continuous monitoring were found to be of little clinical or prognostic value since they were kept below $20 \mathrm{mmHg}$ by rapid initiation of treatment as soon as rises above this value were noted. The need to try other drugs after failure to reduce the ICP signified more severe disease and higher rates of mortality and morbidity.

The mean maximal pressures were significantly increased in both groups of patients. In the patients with cerebral ischaemia however, maximal ICP was not significantly different between survivors and non-survivors. Three of the 6 patients who died did not develop increased ICP while all those who survived in this group developed pronounced increases in ICP during the course of the disease. The prognosis for such patients depends on the severity of brain damage incurred during the ischaemic period and not necessarily on the degree of increased ICP developed later in the course of the disease. Two of the patients in this group who survived, arrested in the intensive care unit and were resuscitated early. Patients with CNS infections developed significantly higher mean maximal pressures than patients with cerebral ischaemia. Mortality in this group of patients however, was significantly lower. In this group of patients a significant difference was found in maximal ICP between survivors and non-survivors. The maintenance of adequate cerebral perfusion pressure to maintain cerebral blood flow is essential for the survival of these patients. Normal cerebral perfusion pressure in newborn infants is $30 \mathrm{mmHg}^{12}$ but the minimum adequate value has not been established. In older children and adults $40 \mathrm{mmHg}$ is thought to be the lower limit of normal. ${ }^{13}$ Those of our patients with cerebral perfusion pressure in the range of $30-40 \mathrm{mmHg}$ had an intact survival. In most of the patients with infections of the CNS we were able to reduce ICP to normal and maintain adequate cerebral perfusion pressure. Four of the 5 patients in this group who died developed intractable increased ICP that could not be reduced by treatment and thus we were unable to preserve adequate cerebral perfusion pressure. We conclude that rapid initiation of treatment of increased ICP in infants with infections of the CNS may prevent further cerebral damage. Inability to reduce increased ICP and maintain adequate cerebral perfusion pressure leads to early death. In infants who sustained prolonged ischaemia, increases in ICP were not directly related to outcome. The prognosis depends mainly on the severity of the initial insult to the brain. Early resuscitation and efforts directed at reinstituting cerebral perfusion pressure may reduce neuronal damage and improve the prognosis. Better methods of monitoring and treating ICP should improve the prognosis in these devastating childhood disorders.

\section{References}

1 Byrnes D P, Ducker T B. Continuous measurement of intracranial pressure in 127 severe head injuries. In: Shulman K, Marmarou A, Miller J D, Becker D P, Hochwald G M, Brock M, eds. Intracranial pressure. IV. Berlin: Springer, 1980: 73-5.

2 Mickell J J, Reigel D H, Cook D R, Binda R E, Safar P. Intracranial pressure: monitoring and normalization therapy in children. Pediatrics 1977; 59: 606-13.

3 Vidyasagar D, Raju T N K, Chiang J. Clinical significance of monitoring anterior fontanel pressure in sick neonates and infants. Pediatrics 1978; 62: 996-9.

4 Raju T N K, Vidyasagar D, Papazafiratou C. Intracranial pressure monitoring in the neonatal ICU. Crit Care Med 1980; 8: 575-81.

5 Philip A G S, Long J G, Donn S M. Intracranial pressure. Sequential measurements in full term and preterm infants. Am J Dis Child 1981; 135: 521-4.

6 Margolis L H, Shaywitz B A. The outcome of prolonged coma in childhood. Pediatrics $1980 ; 65: 477-83$.

7 Horbar J D, Yeager S, Philip A G S, Lucey J F. Effect of application force on noninvasive measurements of intracranial pressure. Pediatrics 1980; 66: 455-7.

8 Goitein K J, Amit Y. Percutaneous placement of subdural catheter for measurement of intracranial pressure in small children. Crit Care Med 1982; 10: 46-8.

- Jennett B, Bond M. Assesment of outcome after severe brain damage. A practical scale. Lancet 1975; i: 480-4.

10 Raju T N K, Vidyasagar D, Torres C, Grundy D, Bennett E J. Intracranial pressure during intubation and anesthesia. J Pediatr 1980;96: 860-2.

11 Fuhrmeister U, Ruether P, Dommasch D, Gaab M. Alterations of CSF hydrodynamics following meningitis and subarachnoid hemorrhage. In: Shulman $\mathbf{K}$, Marmarou A, Miller J D, Becker D P, Hochwald G M, Brock M, eds. Intracranial pressure. IV. Berlin: Springer, 1980: 241-3.

12 Raju T N K, Doshi U V, Vidyasagar D. Cerebral perfusion pressure studies in healthy preterm and term newborn infants. J Pediatr 1982; 100: 139-42.

13 Miller J D, Stanek A, Langfitt T W. Concept of cerebral perfusion pressure and vascular compression during intracranial hypertension. Prog Brain Res 1972; 35: 411-32.

Correspondence to $\mathrm{Dr} \mathrm{K} \mathbf{J}$ Goitein, Paediatric Intensive Care Unit, Hadassah University Hospital, Jerusalem 91120, Israel.

Received 30 September 1982 